\title{
Rapid detection of gene encoding oxa carbapenemases in Acinetobacter using multiplex PCR
}

\author{
Lavanya $\mathbf{P}^{1}$, Uma A. $\mathbf{N}^{2, *}$
}

${ }^{1}$ Department of Microbiology,

Faculty of Allied Health

Sciences,

${ }^{2}$ Genetic Division, Department of Anatomy, Mahatma Gandhi Medical College and Research Institute, Sri Balaji Vidyapeeth,

(Deemed to be University), Pillaiyarkuppam, Puducherry-607402.

For Correspondence

${ }^{*}$ Dr. Uma AN,

Email:uma4002@yahoo.com Date of

Submisssion: 31-01-2019 Acceptance: 26-02-2019

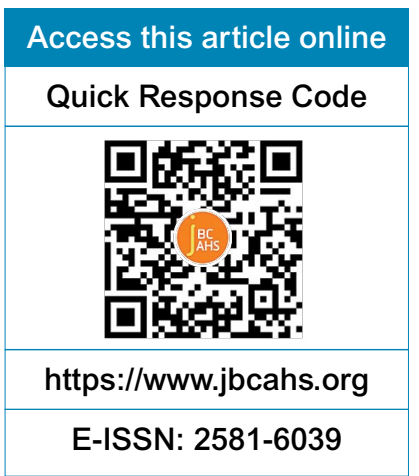

\section{ABSTRACT}

Background and Objective: Acinetobacter, has been identified as an important pathogen in nosocomial outbreaks with high levels of emerging drug resistance. The present study was conducted in Acinetobacter spp to find out the utility of the multiplex PCR assay, which may be used as a useful technique in the early detection \& prevention of $\mathrm{bla}_{\mathrm{OXA}-23}$ and $\mathrm{bla}_{\mathrm{OXA}-58}$ gene harbouring in clinical isolates taken from the patients coming to a tertiary care hospital.

Material and Methods: Strains of Acinetobacter collected from different clinical samples were subjected to antimicrobial susceptibility testing. Strains which were found showing resistance to imipenem by both disk diffusion and minimum inhibitory concentration (MIC), were analysed for the presence bla $_{\text {OXA-23 }}$ and bla $\mathrm{OXX}-58$ (CLASS D) by using multiplex PCR.

Results: Among 175 strains of Acinetobacter collected from the clinical samples, 45 strains showed imipenem resistance, both by disk diffusion and MIC out of which $19(42.2 \%)$ were positive for bla $\mathrm{OXA}-58$ gene and all strains $45(100 \%)$ were positive for bla $_{\text {OXA-23 }}$ gene.

Conclusion: The present study shows that there is dissemination of genes produced carbapenem resistant in the Acinetobacter isolates. This scientific evidence can be used to limit the spread of such strains in hospital settings as well as in the community, and also may help in initiating specific hospital infection control measures.

\section{Keywords:}

OXA carbapenemases, Imipenem, Acinetobacter, PCR

\section{INTRODUCTION}

Acinetobacter baumannii, an emerging pathogen of healthcare centers, shows intrinsic as well as acquired drugresistance mechanisms. ${ }^{1}$ Acinetobacter spp are gram negative non-fermentative bacteria. Clinical manifestations of Acinetobacter infections includes, hospital acquired pneumonia, blood stream infections, urinary tract infection, meningitis and wound infection. $^{2}$ Because of frequent resistance to the aminoglycosides and third generation cephalosporin, carbapenem are widely used for managing Acinetobacter infections. ${ }^{3}$ The emergence of carbapenem resistance in Acinetobacter spp is a significant public health concern because of limited option of antibiotic treatment. ${ }^{4}$ Carbapenamases found in Acinetobacter may belong to class B (Metallo enzymes) or class D (OXA enzymes). ${ }^{5}$ The OXA carbapenamases of Acinetobacter is divided into four phylogenetic subgroups namely bla ${ }_{\text {OXA-23 }}$ like, bla $_{\text {OXA-24 }}$ like, bla ${ }_{\text {OXA-51 } 1}$ and bla OXA-58. A . study done in India has reported the emergence of OXA carbapenemases in different enterobacterial species and also in Acinetobacter. ${ }^{6}$

Thus, the aim of the present study was to determine antibiotic susceptibility profile, antibiotic resistance genes and genetic mechanism of carbapenem resistance of A.baumannii in clinical isolates at a tertiary care hospital in 
South India. Also the study was carried out to find out if there can be a dissemination of carbapenem

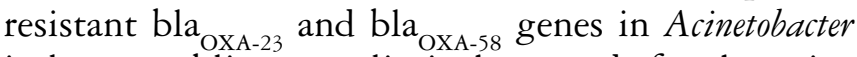
isolates, enabling us to limit the spread of such strains in hospital settings as well as in the community, and also help in initiating specific hospital infection control measures.

\section{MATERIALS AND METHODS}

The Strains of Acinetobacter were isolated from inpatients coming to the tertiary care hospital in South India, were collected from different samples i.e., sputum, tracheal aspirate, wound swab, blood, urine etc. All clinical isolates, identified to be non lactose fermenting, glucose non-acidifier, Gram negative bacilli, catalase positive, oxidase negative and citrate positive were taken up for the study.

\section{DETECTION OF IMIPENEM RESISTANT}

Antimicrobial susceptibility testing was done following Kirby Bauer disk diffusion method using routine drugs including imipenem as per Clinical and Laboratory Standards Institute (CLSI) guidelines. Modified Hodge test and Imipenem EDTA disk synergy test was used to detect carbapenemase production from isolates of Acinetobacter spp and further tested by Minimum inhibitory concentration (MIC) by agar dilution method. The antimicrobial concentration ranges tested were from 0.03 to $128 \mathrm{~g} / \mathrm{ml}$ for imipenem.

\section{DETECTION OF GENES BY PCR}

DNA extraction was done using multiplex PCR assay on imipenem resistance strains of Acinetobacter, by both disk diffusion and agar dilution method to detect bla $_{\text {OXA-23 }}$ and bla ${ }_{\text {OXA-58 }}$ carbapenemases encoding genes as shown below

\section{OXA 23-(453bp)-F-AGTATTGGGGCTTGTGCT R-AACTTCCGTGCCTATTTG}

\section{OXA 58-(233bp)-F-ATGCAAAGTGAATTGCAACG R-CCCCAGCCACTTTTAGCATA}

Amplifications conditions followed in the methodology were, initial denaturation at $94^{\circ} \mathrm{C}$ for 3 mins, 30 cycles of $94^{\circ} \mathrm{C}$ for $1 \mathrm{~min}, 55^{\circ} \mathrm{C}$ for 1 min, $72^{\circ} \mathrm{C}$ for $1 \mathrm{~min}$ and final extension at $72^{\circ} \mathrm{C}$ for 5 mins.

\section{RESULTS}

175 strains of Acinetobacter were isolated from different clinical samples. Among the 175 strains, 61 were found to be resistant to imipenem EDTA disk synergy test. Of these 61 strains, 45 showed resistance to imipenem by MIC agar dilution method (Figure 1). Subjecting these 45 strains of Acinetobacter to Multiplex PCR, showed that all the $45(100 \%)$ strains were positive for bla ${ }_{\text {OXA-23 }}$ gene among which $19(42.2 \%)$ of them were also positive for $\mathrm{bla}_{\text {OXA-58 }}$ gene (Figure 2).

Figure 1: Minimum Inhibitory Concentration (MIC) method for Imipenem

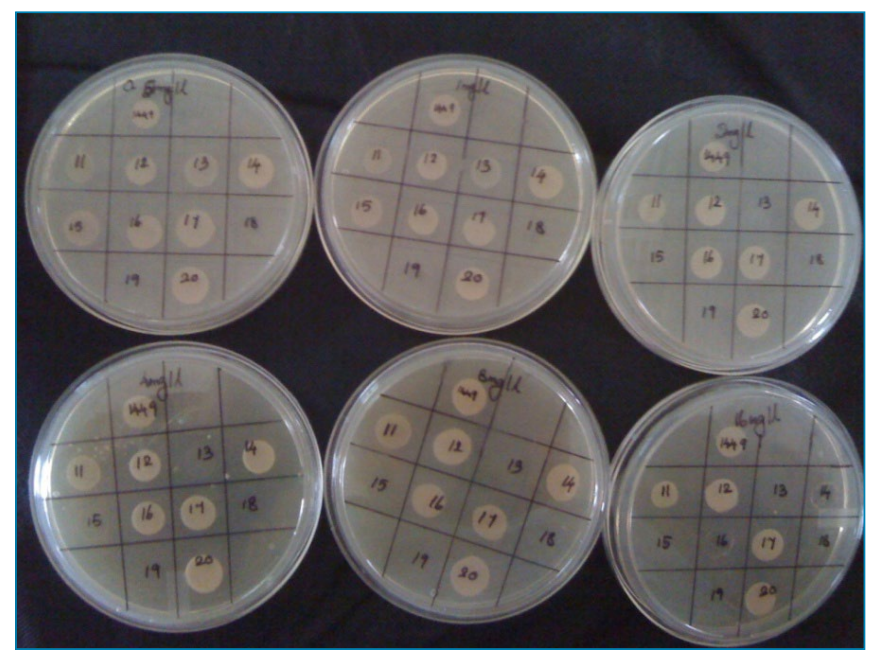

Figure 2: Detection of bla ${ }_{\mathrm{OXA}-23}$ and bla ${ }_{\mathrm{OXA}-58}$ gene by molecular methods

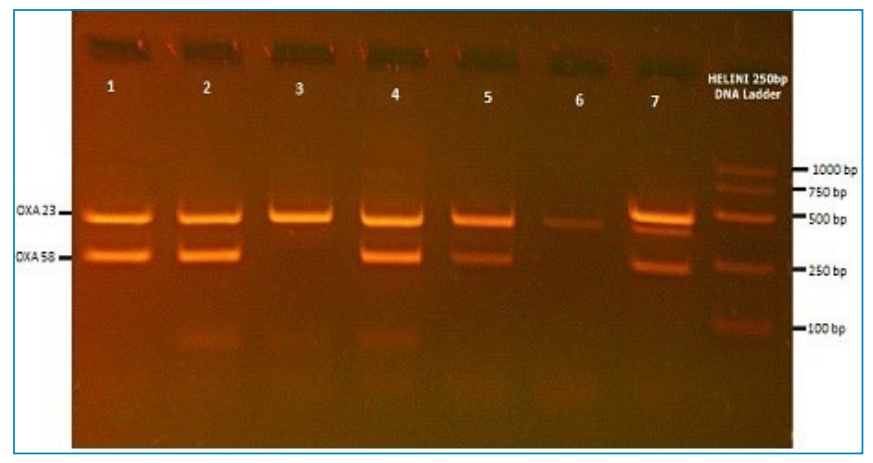

\section{DISCUSSION}

The high antimicrobial resistance of Acinetobacter spp emerged as a nosocomial pathogen worldwide. The need for strategic measures to deal with this challenge is to find a solution to minimize antimicrobial misuse within both clinical and non-clinical settings has been stressed by many medical professionals. ${ }^{8}$ In 1993 , 
acquired OXA carbapenemases was reported for the first time and subsequently after that emergence and spread of OXA enzymes have been reported worldwide. ${ }^{9}$

The bla ${ }_{\text {OXA-23 }}$ gene is one of the most prevalent carbapenemases encoding genes reported worldwide, which can be located on chromosomes of Acinetobacter plasmids. ${ }^{10}$ Similarly in the present study all the strains were found to be positive for bla ${ }_{\mathrm{OXA}-23}$. Many reports have indicated that in United Kingdom, that bla $_{\text {OXA-23 }}$ and bla ${ }_{\text {OXA-58 }}$ are most frequently detected in Acinetobacter. And as reported by earlier studies, bla $_{\text {OXA-58 }}$ may be present along with bla ${ }_{\text {OXA-23 }}$ which is responsible for reduced susceptibility to carbapenem group of drugs, the finding is very much similar to our study.

NDM-1 metallo- $\beta$-lactamase was detected among enterobacteriacae and also in Acinetobacter baumannii especially in India and Pakistan. A study conducted in India showed the co-existence of bla ${ }_{\text {OXA-23 }}$ and NDM-1 in clinical isolates of Acinetobacter baumannii. ${ }^{11}$ In our study we used a cost effective multiplex PCR technique and observed only the emergence of bla ${ }_{\text {OXA-23 }}$ and bla $_{\text {OXA-58 }}$ in imipenem resistant Acinetobacter isolates.

With increase in drug resistance in Acinetobacter, resistance surveillance has become increasingly important. Hence both the phenotypic and genotypic methods are important to detect the carbapenem resistance in Acinetobacter. Thus the cost effective multiplex PCR technique may be very helpful to detect carbapenemase resistant genes since we get the results within a short duration. ${ }^{12}$ Technique like multiplex PCR would also help us to monitor the emergence and spread of carbapenem resistant Acinetobacter spp. ${ }^{13}$ OXA-type carbapenemases which will further limit chemotherapeutic options that threatens the public health. ${ }^{14}$

\section{CONCLUSION}

The study successfully demonstrates the utility of cost effective multiplex PCR assay as a useful technique in the detection of bla ${ }_{\text {OXA-23 }}$ and bla ${ }_{\text {OXA-58 }}$ harbouring clinical isolates of Acinetobacter. Because of the difficulty in treating patients infected with OXA carbapenemases genes harbouring bacterial pathogens, it is necessary to identify such strains as soon as possible. Moreover, studying the epidemiology of such resistant strains helps us to limit the spread of such strains in hospital settings as well as in the community, and also helps in initiating specific hospital infection control measures.

\section{CONFLICTS OF INTEREST}

None

\section{References}

1. Yamamoto M, Nagao M, Matsumura Y, Matsushima A, Ito Y, Takakura S, et al. Interspecies dissemination of a novel class 1 integron carrying blaIMP-19 among Acinetobacter species in Japan. J Antimicrob Chemother. 2011;66:2480-3.

2. Gur D, Korten V, Unal S, Deshpande LM, Castanheira M. Increasing carbapenem resistance due to the clonal dissemination of oxacillinase (OXA-23 and OXA-58) -producing Acinetobacter baumannii: report from the Turkish SENTRY Program sites. J Med Microbiol. 2008;57(Pt 12):1529-32.

3. Coelho J, Woodford N, Turton J,Livemore DM. Multiresistant Acinetobacter in the UK: how big a threat? J Hosp infect. 2004;58:167-9.

4. Fournier PE, Richet H. The epidemiology and control of Acinetobacter baumannii in health care facilities. Clin infect Dis. 2006;42:692-9.

5. Weinstein A.A. Epidemiology and control of nosocomial infections in adult intensive care units. Am J Med. 1991;91(3B):179S-184S.

6. Rolain JM, Parola P, Cornaglia G, New Delhi metallo b-lactamase (NDM-1) towards a new pandemia Clin Microbial Infect. 2010;16:1699-701.

7. Pelag AY, Seifert H,Peterson DL. Acinetobacter baumannii emergence of a successful pathogen.Clin Microbiol Rev. 2008;21:538-82.

8. Ofori-Asenso R. "When the Bug Cannot Be Killed"-The Rising Challenge of Antimicrobial Resistance. Medicines (Basel). 2017;4.pii: E40.

9. Kusradze Ia, Diene SM, Goderdzishvili M, Rolain JM. Molecular detection of OXA carbapenemases genes in multi-drug resistant Acinetobacter baumannii isolates from Iraq and Georgia. Int J Antimicrob. 2011;38:164-8.

10. Mugnier PD, Poirel L, Naas T, Nordmann P. World wide dissemination of the bla ${ }_{\text {OXA-23 }}$ carbapenemases gene of Acinetobacter baumannii. Emerg infect Dis. 2010;16:35-40.

11. Karthikeyan K,Thirunarayan MA,Krishnan P Coexistence of bla ${ }_{\mathrm{OXA}-23}$ with bla $\mathrm{NDM}-1$ and armA in clinical isolates of Acinetobacter baumanni from India. J Antimicrobial Chemotherapy. 2010;65:2253-4.

12. Nemec, A.,L.Janda,O.Melter, L.Dijkshoorn. Genotypic and phenotypic similarity of multiresistant Acinetobacter baumanni isolates in the Czech Republic. J.Med.Microbiol. 1999;48.287-96.

13. Woodford N, Ellington MJ, Coelho JM, Turton IF, Ward ME. Brown S, et al. Multiplex PCR for encoding prevalent OXA carbapenemases in Acinetobacter spp. Int J Antimicrob. 2006;27:351-3.

14. Joshi PR, Acharya M, Kakshapati T, Leungtongkam U, Thummeepak $\mathrm{R}$, Sitthisak S. Co-existence of blaOXA-23 and blaNDM-1 genes of Acinetobacter baumannii isolated from Nepal: antimicrobial resistance and clinical significance. Antimicrob Resist Infect Control. 2017;6:21. 